\title{
FORMULATION AND EVALUATION OF TRANSDERMAL PATCHES OF ATENOLOL
}

\author{
Uttam Budhathoki*, Mail Kshitij Gartoulla, Shailendra Shakya
}

Department of Pharmacy, Kathmandu University, Dhulikhel, Kavre, Nepal. GPO box 6250 (Kathmandu)

Country Nepal.

Submitted: $13-08-2016$

Revised: $05-10-2016$

Accepted: $19-10-2016$

*Corresponding author

Uttam Budhathoki

Email:

uttam@ku.edu.np

\begin{abstract}
This study was carried out to develop matrix based transdermal patches containing Atenolol. A 2 factors HPMC (hydroxyl propyl methyl cellulose) K4M and PVP (Polyvinyl Pyrolidone) 3 level $\left(2^{3}\right)$ factorial design was done using Design Expert $\AA$ which gave 13 experiments. The patches were prepared by Solvent casting method. Propylene glycol (3\%) and Tween 80 $(6 \%)$ were used as plasticizer and permeation enhancer respectively. Physicochemical characteristics and In-Vitro permeation study of formulated transdermal patches were carried out. Contour plot suggested $770 \mathrm{mg}$ of PVP and $265 \mathrm{mg}$ of HPMC K4M in Optimized formulation.
\end{abstract}

Keywords: Atenolol, Transdermal Patches, In-Vitro permeation study, permeation enhancer, HPMC, PVP

\section{INTRODUCTION}

Transdermal drug delivery system (TDDS) is one of the advantageous routes of drug administration (Ibrahim et al., 2014). TDDS is particularly important because it bypasses first-pass metabolism. However, this route of delivery is challenged by the barrier nature of skin. Various medicines are available in TDDS (Sun et al., 1997).

TDDS basically consists of adhesive drug-containing devices of defined surface area that delivers a predetermined amount of drug to the intact skin at a preprogrammed rate (Ahmed et al., 2011), which is able to penetrate through different layers of skin to reach the systemic circulation (Chander et al., 2013). Currently, the transdermal route, along with oral treatment, ranks as the most successful innovative research area in drug delivery (Saroha et al, 2011). Baking layer, drug containing layer, rate controlling membrane, adhesive and release liner are the components of TDDS (Jhawat et al, 2013; Prejeet et al., 2011; Chein et al., 1987) though all layers may not be available in all types of TDDS as there are several types of transdermal patches. There are single layer drug in adhesive, multilayer drug in adhesive, vapour patch, reservoir system and matrix system (Aulton, 2002). Similarly natural polymers, synthetic polymers, synthetic elastomers and biopolymers have been used in TDDS (Sharma et al., 2012). The biological properties of drug for preparing transdermal patch should be of short half-life, should not produce allergic response and the drug should be potent with a daily dose of the order of a few $\mathrm{mg} / \mathrm{day}$ (Muller et al., 2003). Substances which temporarily diminish the impermeability of the skin are known as permeation enhancers. As the epidermis is the main barrier for penetration of the drug, several chemical enhancers such as sulphoxide, alcohols, fatty acids, polyols, ureas and physical enhancers such as sonophorosis, electroporation, iontophorosis, magnetophorosis have been used in TDDS (Finnin et al., 1999; Funke et al., 2002; Taylor et al., 2002).

This study has been carried out to incorporate Atenolol in matrix-based TDDS. Atenolol is one of the commonly used antihypertensive drugs, which acts as a betaadrenergic receptor blocking agent. After oral administration, the elimination half life of the drug is $6-7 \mathrm{~h}$. The absolute bioavailability is approximately $50 \%$ due to first pass metabolism (Ghosh et al., 2001; Jain et al, 1993). Therefore an alternative route (TDDS) is chosen for the delivery of drug.

\section{MATERIALS AND METHODS}

Atenolol, HPMC K4M, Tween 80, Sodium hydroxide, and Potassium dihydrogen phosphate and methanol were used during the study. Propylene glycol (3\%) was used as plasticizer and Tween $80(6 \%)$ as permeation enhancer. 
Formulation and Evaluation of Transdermal Patches

Table I. A $2^{3}$ factorial design for formulation of matrix based transdermal patches

\begin{tabular}{lccccccccccccc}
\hline Ingredient & P1 & P2 & P3 & P4 & P5 & P6 & P7 & P8 & P9 & P10 & P11 & P12 & P13 \\
\hline Atenolol (mg) & 20 & 20 & 20 & 20 & 20 & 20 & 20 & 20 & 20 & 20 & 20 & 20 & 20 \\
HPMC K4M (mg) & 55.17 & 37.5 & 37.5 & 37.5 & 37.5 & 37.5 & 50 & 25 & 37.5 & 37.5 & 50 & 19.83 & 25 \\
PVP (mg) & 70 & 70 & 70 & 70 & 13.36 & 6.36 & 115 & 115 & 70 & 70 & 25 & 70 & 25 \\
Tween 80 (\%w/w) & 10 & 10 & 10 & 10 & 10 & 10 & 10 & 10 & 10 & 10 & 10 & 10 & 10 \\
PEG (\%w/w) & 5 & 5 & 5 & 5 & 5 & 5 & 5 & 5 & 5 & 5 & 5 & 5 & 5 \\
Methanol (mL) & 1.43 & 1.43 & 1.43 & 1.43 & 1.43 & 1.43 & 1.43 & 1.43 & 1.43 & 1.43 & 1.43 & 1.43 & 1.43 \\
Water (mL) & 1.43 & 1.43 & 1.43 & 1.43 & 1.43 & 1.43 & 1.43 & 1.43 & 1.43 & 1.43 & 1.43 & 1.43 & 1.43 \\
\hline
\end{tabular}

\section{Preparation of standard curve}

Absorbance of five known concentrations of Atenolol (20, 40, 60, 80 and $100 \mu \mathrm{g} / \mathrm{mL}$ ) in Phosphate buffer $\mathrm{pH} 7.4$ were measured in UV-Visible spectrophotometer at $\mathrm{V}_{\max }=275 \mathrm{~nm}$. Then Concentration vs Absorbance curve was plotted and correlation coefficient $\left(\mathrm{r}^{2}\right)$ value with equation of the curve was determined.

\section{Fabrication of Transdermal Patches}

A 2 factor 3 level (23) factorial design was done using Design Expert 9.1 which gave 13 experiments (Table L). Then, matrix-based transdermal patches of Atenolol were prepared by solvent casting method using aluminum foil as a backing layer. The two independent factors were HPMC K4M and PVP. The mixture of solvent casting method consisted of solvent (distilled water and methanol), permeation enhancer (Tween $80 ; 10 \%$ of total weight of drug + polymer) and plasticizer (PEG; $5 \%$ of total volume of solvent). Dose of drug was adjusted in such a way that circular patch $\left(4 \mathrm{~cm}^{2}\right)$ consisted of $20 \mathrm{mg}$ of Atenolol.

\section{Evaluation of transdermal patches Weight variation}

The matrix film was cut into $4 \mathrm{~cm}^{2}$. Weight of five patches was taken individually and averaged (mean \pm standard deviation).

\section{Thickness variation}

The matrix film was cut into $4 \mathrm{~cm}^{2}$. Thickness of five patches was measured individually by digital vernier caliper and then averaged (mean \pm standard deviation).

\section{Percentage of moisture absorbed}

Accurately weighed patches were placed in a desiccators for $72 \mathrm{~h}$. After $72 \mathrm{~h}$, the patches were reweighed and the percentage moisture absorption was calculated using the formula:

$\%$ Moisture content $=\frac{\text { Initial weight }- \text { final weight }}{\text { Initial weight }} \times 100 \%$

\section{Folding endurance of the patches}

Patches $\left(4 \mathrm{~cm}^{2}\right)$ were cut and repeatedly folded at the same place till it was broken $(\mathrm{n}=3)$. The number of times the folding required to be broken was recorded as folding endurance.

\section{Drug content uniformity}

A patch $\left(4 \mathrm{~cm}^{2}\right)$ was kept in beaker $(100 \mathrm{~mL})$ with methanol and stirred continuously using a magnetic stirrer for $3 \mathrm{~h}$. The sample $(1 \mathrm{~mL})$ was diluted with methanol in $50 \mathrm{~mL}$ volumetric flask. The absorbance was taken spectrophotometrically at $275 \mathrm{~nm}$ using methanol as a blank. The drug content was calculated by using the equation obtained from the standard calibration curve (Figure 1). The experiment for each formulation was triplicated.

\section{Drug permeation study}

The in-vitro permeation study was carried out by using Franz Diffusion Cell and cellophane membrane. The Franz diffusion cell has receptor compartment of volume $50 \mathrm{~mL}$ and internal diameter of $4.5 \mathrm{~cm}$. A Transdermal patch was placed on one side of cellophane membrane. The medium on the receptor side was phosphate buffer $\mathrm{pH}$ 7.4. The temperature was maintained at $37 \pm 2^{\circ} \mathrm{C}$. The receptor fluid was stirred by magnetic bead placed in the diffusion cell. During each sampling interval, samples were withdrawn and replaced by equal volumes of fresh receptor fluid. 


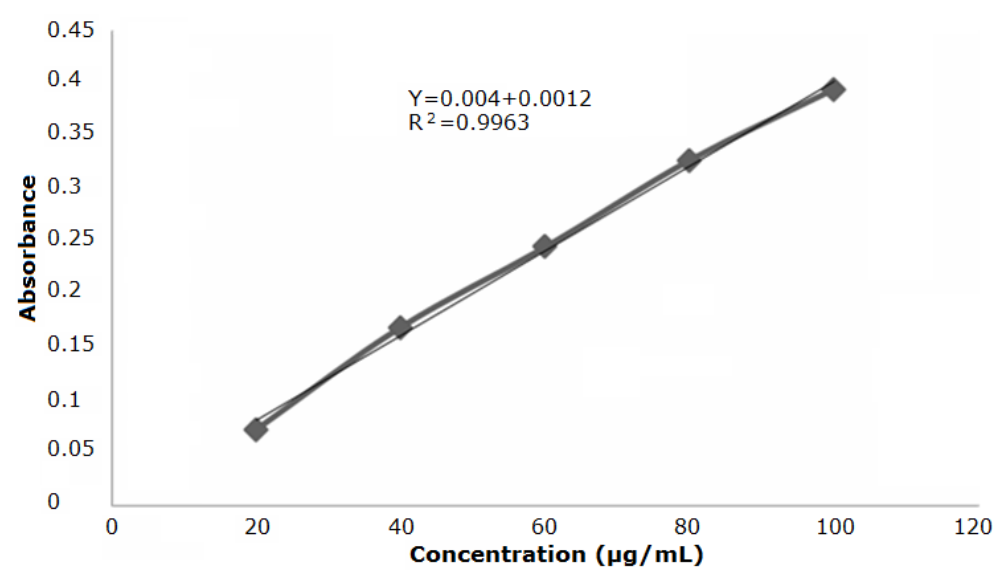

Figure 1. Standard curve of Atenolol

The samples $(1 \mathrm{~mL})$ was withdrawn at predetermined time interval and diluted with phosphate buffer $\mathrm{pH} 7.4$ in $25 \mathrm{~mL}$ volumetric flask. The sample was analyzed spectrophotometrically at $275 \mathrm{~nm}$.

\section{Drug dissolution study}

Dissolution was performed by attaching the patches to the lower surface of a $50 \mathrm{~mL}$ beaker using a dual side adhesive tape. The beaker was held above another beaker $(250 \mathrm{~mL})$ by a plastic cap having a hole centrally. The above beaker was held in a cap in such a way that the patch was just touching the medium at another beaker. The receiver beaker was filled with phosphate buffer $\mathrm{pH}$ 7.4. The temperature was maintained at $37 \pm 2{ }^{\circ} \mathrm{C}$ and constantly agitated by a magnetic stirrer. Sample were withdrawn at 1, 2, 4,6 and $8 \mathrm{~h}$ and replaced by fresh phosphate buffer $\mathrm{pH}$ 7.4. The withdrawn samples were suitably diluted and analysed spectophotometrically at $275 \mathrm{~nm}$.

\section{RESULTS AND DISCUSSION}

Percentage moisture lost and percentage moisture absorbed were found to be from 5.47 to 16.74 and 5.1 to 9.23 , respectively. The minimum and maximum folding endurance were 77 (P5) and 102 (P7), respectively. Drug content of all formulation was found in between 18.67 \pm 0.48 (P10) and 20.93 $\pm 1.32 \mathrm{mg}$ (P8) (Table II and III). The highest and lowest cumulative percentage drug releases in $8 \mathrm{~h}$ were shown by P7 $(87.4 \pm 2.20)$ and P6 (74.3 \pm 2.17$)$, respectively (Figure 2). The highest cumulative percentage drug permeation in $12 \mathrm{~h}$ was shown by P7 (93.70 \pm 1.88$)$ while the lowest permeation was shown by P11 (76.50 1 ) (Figure 3). The contour plot for optimized formulation generated by using Design expert 9.0.3 predicted $770 \mathrm{mg}$ for PVP and $265 \mathrm{mg}$ for HPMC K4M based on 32.8, 49.2, 68 and $80.85 \%$ required cumulative percentage drug release in optimized formulation in 2, 4, 6 and 8h respectively (Bangale et al., 2010) (Figure 4). Cumulative percentage drug release for optimized formulation was found to be 30.5 , 48.6, 67.8 and $81 \%$ for 2, 4, 6 and $8 \mathrm{hr}$ respectively (Figure 5).

Different formulations(p5, and p7) have different folding endurance with same amount plasticizer (Table I) suggest that patch should be made in controlled humidity condition. the different folding endurance could be due to different amount of moisture with patch. Optimized formulation (PVP $=770 \mathrm{mg}$ and HPMC K4M = 265mg) developed by Contour plot gave dissimilarity factor towards lower end (1) and similarity factor tow ards higher end (90) and suggests that cumulative percentage drug release is similar to the reference data (Bangale et al., 2010). The cumulative percentage drug permeated in $12 \mathrm{~h}$ was found to be the highest for the formulation carrying HPMC K4M and PVP in low ratio $(13: 10$, P7) where as the cumulative percentage of drug permeated in $12 \mathrm{~h}$ was found to be low in the formulation containing high ratio of HPMC K4M and PVP (2:1, P11). 
Table II. Physicochemical properties of matrix-based transdermal patch formulation of Atenolol

\begin{tabular}{cccccccc}
\hline Formulation & $\begin{array}{c}\text { First } \\
\text { Order }\end{array}$ & Higuchi Power & $\begin{array}{c}\mathbf{n} \\
\text { Value }\end{array}$ & $\begin{array}{c}\text { Content Uniformity } \\
\text { (Mean+Std. Dev.) }\end{array}$ & $\begin{array}{c}\text { Disimilarity } \\
\text { factor (f1) }\end{array}$ & $\begin{array}{c}\text { Similarity } \\
\text { factor (f2) }\end{array}$ \\
\hline P1 & 0.99 & 0.999 & 0.998 & 0.662 & $20.10 \pm 1.35$ & 9 & 62 \\
P2 & 0.995 & 0.995 & 0.998 & 0.685 & $20.13 \pm 0.31$ & 15 & 52 \\
P3 & 0.995 & 0.995 & 0.998 & 0.703 & $19.77 \pm 1.00$ & 15 & 53 \\
P4 & 0.998 & 0.998 & 0.997 & 0.698 & $19.07 \pm 1.40$ & 16 & 54 \\
P5 & $0-997$ & 0.998 & 0.989 & 0.732 & $19.43 \pm 0.72$ & 29 & 38 \\
P6 & 0.997 & 0.995 & 0.997 & 0.657 & $20.23 \pm 2.00$ & 34 & 35 \\
P7 & 0.989 & 0.999 & 0.997 & 0.656 & $20.60 \pm 1.61$ & 12 & 56 \\
P8 & 0.994 & 0.995 & 0.997 & 0.672 & $20.93 \pm 1.32$ & 14 & 54 \\
P9 & 0.994 & 0.982 & 0.997 & 0.694 & $18.67 \pm 0.86$ & 14 & 53 \\
P10 & 0.993 & 0.995 & 0.998 & 0.687 & $18.67 \pm 0.48$ & 15 & 61 \\
P11 & 0.979 & 0.979 & 0.99 & 0.737 & $20.60 \pm 1.61$ & 32 & 38 \\
P12 & 0.991 & 0.999 & 0.997 & 0.661 & $19.67 \pm 0.97$ & 20 & 46 \\
P13 & 0.989 & 0.987 & 0.992 & 0.655 & $19.30 \pm 1.10$ & 12 & 66 \\
\hline
\end{tabular}

Table III. Physicochemical properties of matrix-based transdermal patch formulation of Atenolol

\begin{tabular}{ccccccc}
\hline Formulation & $\begin{array}{c}\text { Thickness } \\
\text { (mm) }\end{array}$ & $\begin{array}{c}\text { Weight } \\
\mathbf{( g m )}\end{array}$ & $\begin{array}{c}\text { Folding } \\
\text { Endurance }\end{array}$ & $\begin{array}{c}\text { Moisture } \\
\text { Lost (\%) }\end{array}$ & $\begin{array}{c}\text { Moisture } \\
\text { Absorbed(\%) }\end{array}$ & Zero Order \\
\hline P1 & 0.32 & $0.309 \pm 1.77$ & $98 \pm 1.28$ & 9.12 & 5.36 & $0.961 \pm$ \\
P2 & 0.346 & $0.356 \pm 1.71$ & $83 \pm 1.56$ & 16.1 & 6.1 & $0.997 \pm$ \\
P3 & 0.318 & $0.289 \pm 1.6$ & $82 \pm 1.29$ & 11.82 & 6.85 & $0.969 \pm 1.1$ \\
P4 & 0.332 & $0.028 \pm 2.06$ & $85 \pm 1.44$ & 16.73 & 5.1 & $0.964 \pm 2.06$ \\
P5 & 0.346 & $0.339 \pm 1.5$ & $77 \pm 1.69$ & 7.83 & 6.53 & $0.962 \pm 0.7$ \\
P6 & 0.306 & $0.3 \pm 2.17$ & $83 \pm 1.45$ & 11.76 & 6.8 & $0.959 \pm 1.01$ \\
P7 & 0.32 & $0.301 \pm 2.06$ & $102 \pm 1.06$ & 5.47 & 7.03 & $0.958 \pm 1.79$ \\
P8 & 0.336 & $0.31 \pm 1.59$ & $79 \pm 1.43$ & 13.3 & 7.6 & $0.967 \pm 1.08$ \\
P9 & 0.308 & $0.284 \pm 1.69$ & $81 \pm 0.83$ & 16.74 & 8.82 & $0.968 \pm 2.07$ \\
P10 & 0.33 & $0.352 \pm 1.54$ & $82 \pm 1.9$ & 10.6 & 9.23 & $0.97 \pm 1.59$ \\
P11 & 0.382 & $0.337 \pm$ & 73 & 7 & 6.23 & 0.984 \\
P12 & 0.324 & $0.3 \pm$ & 83 & 12.22 & 6.82 & 0.96 \\
P13 & 0.334 & $0.34 \pm$ & 82 & 10.28 & 6.08 & 0.97 \\
\hline
\end{tabular}

This could be due to low viscosity and hydrophilic nature of PVP. Similarly, high proportion of HPMC K4M : PVP showed decrease in cumulative percentage drug release (37.5:6.36, P6) and vice versa (2:1, P7) (Table I, II and III) which could be due to viscous nature of HPMC K4M. Moreover, addition of PVP into the formulation tends to enhance its release-rate constants (Gupta et al., 2009). This outcome can be attributed to the leaching of the soluble component which leads to the formation of pores and thus a decrease in the mean diffusion path length of drug molecules to release into the dissolution medium (Darwhekar et al., 2011). Thus, higher the proportion of HPMC K4M against PVP, more control will be in both permeation and release rate of Atenolol. All formulations followed first order that was a concentration dependent release.

Drug release from formulations followed first order 1 . The $n$ value of Power law for all formulation was seen to lie between 0.5 to 1.0 which suggests that the drug transport mechanism was anomalous (nonFickian) diffusion (De PK et al., 2011) (Table II and III). Anomalous diffusion could be due to diffusion partially through a swollen matrix and water-filled pores in the formulations. 


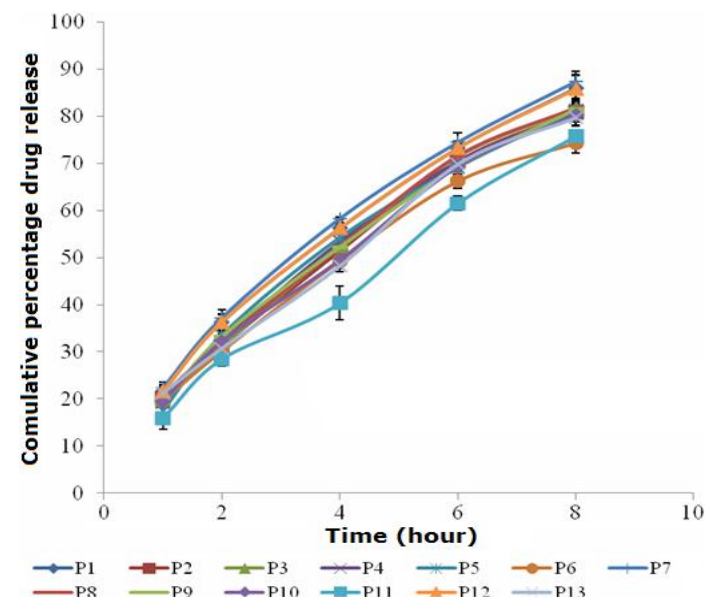

Figure 2. Cumulative percentage drug release vs. time profile of all formulations

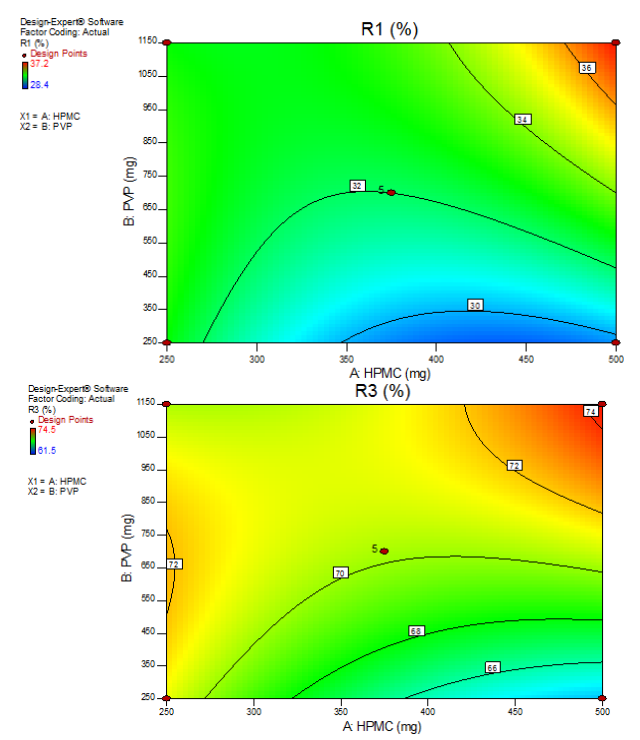

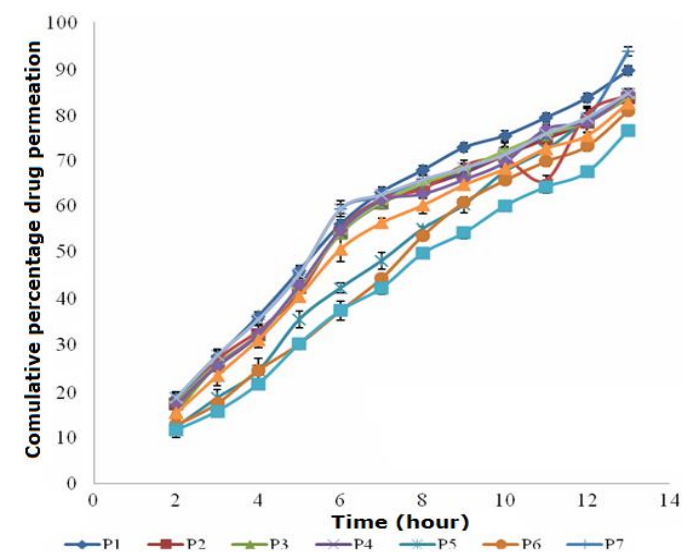

Figure 3. Cumulative percentage drug permeation vs. time profile of all formulations
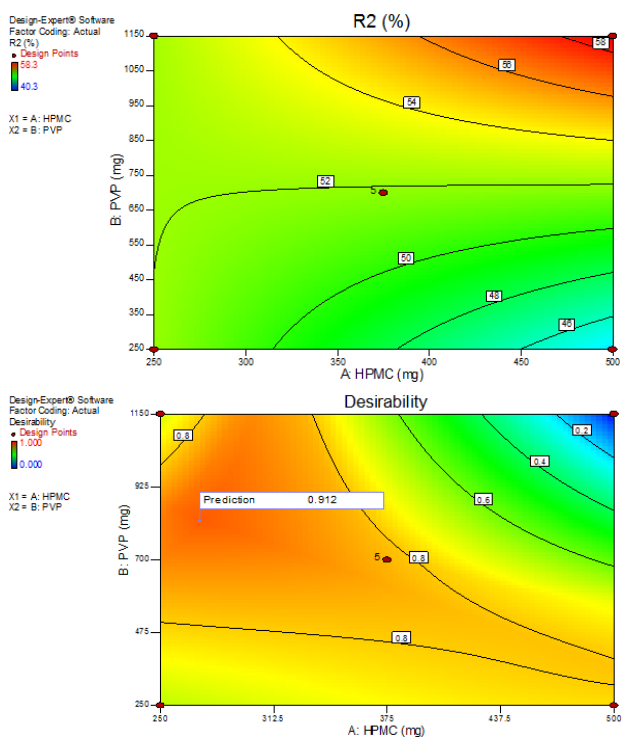

Figure 4. Contour Plot for drug release of PVP vs HPMC K4M at $2^{\text {nd }}(\mathrm{R} 1)$, 4 ${ }^{\text {th }}$ (R2), $6^{\text {th }}$ (R3) and $8^{\text {th }}$ (R4) hour and PVP versus HPMC K4M showing the region of desirability for optimum formulation

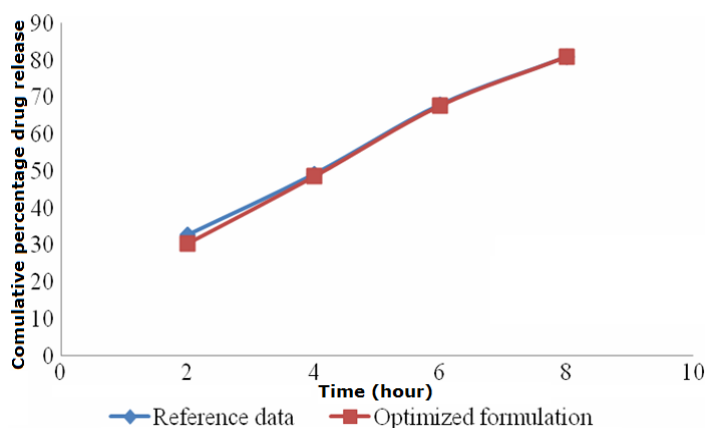

Figure 5. Cumulative percentage drug release of Reference data vs Optimized formulation. 
The similar thickness of all patches indicates the physical uniformity of prepared patches. Folding endurance of all formulations indicates good strength and elasticity and can maintain the integrity with general skin folding (Patel et al, 2013) (Table II and III). The moisture uptake in the formulations is a function of HPMC K4M and PVP. This may be having high affinity for water and induces higher moisture uptake as the HPMC K4M, PVP ratio in the films increased. The moisture absorption was seen to increase with increasing the concentration of HPMC K4M (Ramesh et al., 2015) and PVP as both are hydrophilic in nature. Optimum moisture intake by patches is important as it helps to prevent patches from becoming brittle.

\section{CONCLUSION}

This study demonstrated that atenolol can be formulated in matrix-based transdermal patches with in-vitro experiment. In-vivo study should be carried out to further explore the possibility of these patches.

\section{ACKNOWLEDGEMENT}

The authors would like to acknowledge Vega Pharmaceuticals Pvt. Ltd., Kathmandu for raw materials as gift samples and Karnali College of Health Sciences, Kathmandu for providing consent to use lab for some experiments.

\section{REFE RE NCES}

Ahmed A., Karki NK., Charde RM., Charde MS., 2011. Transdermal drug delivery systems:an overview. Int $J$ of Biomed \& Adv Res. 2(1) : 38-56.

Aulton ME., 2002. Pharmacentics: The science of dosage form design. $2^{\text {nd }}$ ed. Churchill Livingston, London, UK. pp. 499-533.

Bangale GS., Rathinaraj BS., Rajesh KS., Shinde GV., Umalkar DG., Rajveer CH., Kumaraswamy D., Panicker PS., 2010. Design and evaluation of transdermal films of Atenolol. J Chem Pharm Res, 2010. 2(3) : 593-604.

Chein YW., 1987. Transdermal controlled systemic medication. Marcel Dekkar Inc, New York, USA. pp. 159-176.

Darwhekar G., Jain DK., Patidar VK., 2011. Formulation and evaluation of transdermal drug delivery system of clopidogrel bisulphate. Asian J Pharm life Sci. 1(3) : 269-278.

De PK., Paul J., Dey SK., Dinda SC., Rakshit S., 2011. Formulation, physic-chemical characterization and release kinetic study of antihypertensive transdermal patches. Der Pharm Sin. 2(5) : 98-109.

Finnin BC., Morgan TM., 1999. Transdermal penetration enhancers: applications, limitations, and potential. J Pharm Sci, 88(10) : 955-958.

Funke AP., Schiller R., Motzkus HW., Günther C., Müller RH., Lipp R., 2002. Transdermal delivery of highly lipophilic drugs: In vitro fluxes of antiestrogens, permeation enhancers and solvents from liquid formulations. Pharm Res. 19(5) : 661-668.

Ghosh B., Reddy LH., 2001. Effect of physicochemical parameters on skin permeability of antihypertensive. Indian J Exp Biol. 39(7) : 710-714.

Gupta JRD., Irchhiaya R., Garud N., Tripathi P., Dubey P., Patel JR., 2009. Formulation and evaluation of matrix type transdermal patches of glibenclamide. Int J Pharm Sci Drug Res. 1(1): 46-50.

Ibrahim SA., 2014. Spray-on transdermal drug delivery system. Expert opin Drug Deliv. 17 $: 1-11$.

Jain GK., Kaul JL., Agrawal SS., 1993. In vitro transdermal delivery of atenolol using mouse and guinea pig. Indian J Exp Biol, 31 (8): 691-693.

Jhawat VC., Saini V., Kamboj S., Maggon N., 2013. Transdermal drug delivery systems: Approaches and Advancements in Drug Absorption through skin. Int J Pharm Sci Rev Res. 20(1) : 47-56.

Jhawat VC., Saini V., Kamboj S., Maggon N., 2013. Transdermal drug delivery systems: approaches and advancements in drug absorption through skin. Int J Pharm Sci Rev Res. 20(1) : 47-56.

Muller B., Kasper M., Surber C., Imanidis G., 2003. Permeation, metabolism and site of action concentration of nicotinic acid derivatives in human skin: correllation with topical pharmacological effect. Eur J Pharm Sci. 20(2) : 181-195. 
Patel HV., Bhatt J., Patel NK., 2013. Design and development of transdermal drug delivery for anti-hypertensive drug using different polymeric system. Int J Pharm Chem Sci. 2(2) : 942-949.

Premjeet S., Bilandi A., Sahil K., Akanksha M., 2011 Transdermal drug delivery system (patches), applications in present scenario: Int J Res Pharm Chem. 1(4) : 1139-1151.

Ramesh Y., Anjana AKM., Manjula DB., Sankeerthana K., Sri LP., Vasanthi A., 2015. Formulation and evaluation of atenolol transdermal patches. Creative J Pharm Res. 1(2) : 55-65.

Saroha K., Yadav B., Sharma B., 2011. Transdermal patch: a discrete dosage form, Int J Curr Pharm Res. 3(3) : 98-108.
Sharma N, Parashar B., Sharma S., Mahajan U., 2012. Blooming pharma industry with transdermal drug delivery system, Indo Global J Pharm Sci. 2(3) : 262-278.

Sun YM., Huang JJ., Lin FC., Lai JY., 1997. Composite poly (2-hydroxyethyl Methacrylate) membranes as ratecontrolling barriers for transdermal applications. Biomaterial. 18(7) : 527-533.

Taylor LJ., Lee RS., Long M., Rawlings AV., Tubek J., Whitehead L., Moss GP., 2002. Effect of occlusion on the percutaneous penetration of linoleic acid and glycerol. Int J Pharm. 249(1-2) : 157164. 